\title{
Pathophysiological mechanisms of catecholamine and cocaine-mediated cardiotoxicity
}

\author{
Lucas Liaudet $\cdot$ Belinda Calderari • \\ Pal Pacher
}

Published online: 8 January 2014

(C) Springer Science+Business Media New York 2014

\begin{abstract}
Overactivation of the sympatho-adrenergic system is an essential mechanism providing short-term adaptation to the stressful conditions of critical illnesses. In the same way, the administration of exogenous catecholamines is mandatory to support the failing circulation in acutely ill patients. In contrast to these short-term benefits, prolonged adrenergic stress is detrimental to the cardiovascular system by initiating a series of adverse effects triggering significant cardiotoxicity, whose pathophysiological mechanisms are complex and only partially elucidated. In addition to the development of myocardial oxygen supply/demand imbalance induced by the sustained activation of adrenergic receptors, catecholamines can damage cardiomyocytes by fostering mitochondrial dysfunction, via two main mechanisms. The first one is calcium overload, consecutive to $\beta$-adrenergic receptormediated activation of protein kinase $\mathrm{A}$ and subsequent phosphorylation of multiple $\mathrm{Ca}^{2+}$-cycling proteins. The second one is oxidative stress, primarily related to the transformation of catecholamines into "aminochromes," which undergo redox cycling in mitochondria to generate copious amounts of oxygen-derived free radicals. In turn, calcium overload and oxidative stress promote mitochondrial permeability transition and cardiomyocyte cell death, both via the apoptotic and necrotic pathways. Comparable mechanisms of myocardial toxicity, including marked
\end{abstract}

L. Liaudet $(\bowtie) \cdot$ B. Calderari

Department of Intensive Care Medicine and Burn Center,

Faculty of Biology and Medicine, University Hospital Medical

Center, BH 08-621, 1010 Lausanne, Switzerland

e-mail: lucas.liaudet@chuv.ch

P. Pacher

The Laboratory of Physiologic Studies, NIH/NIAA, Bethesda, MD 20892-9413, USA oxidative stress and mitochondrial dysfunction, have been reported with the use of cocaine, a common recreational drug with potent sympathomimetic activity. The aim of the current review is to present in detail the pathophysiological processes underlying the development of catecholamine and cocaine-induced cardiomyopathy, as such conditions may be frequently encountered in the clinical practice of cardiologists and ICU specialists.

Keywords Catecholamines - Cocaine - Cardiomyopathy · Oxidative stress $\cdot$ Mitochondria $\cdot$ Signaling $\cdot$ Heart failure

\section{Introduction}

Most critically ill patients disclose a hyperadrenergic state as a primary adaptive response to the acute stress imposed to their organism. In addition, exogenous catecholamines represent the first-line therapeutic agents to improve cardiovascular dysfunction in intensive care unit (ICU) patients. Whereas a prompt surge of sympathetic stimulation is essential for survival under conditions of acute circulatory failure, prolonged exposure to elevated levels of catecholamines may, by contrast, become maladaptive and can result in significant adverse effects [1]. Of primary concern, sympathetic overstimulation promotes cardiac toxicity, whose detrimental consequences have been well established in the field of chronic heart failure syndromes [2]. With respect to acute illnesses, this issue has recently begun to attract particular attention, with the publication of several studies reporting adverse cardiovascular effects, and possibly increased mortality, associated with catecholamine administration [3-5]. The mechanisms responsible for the cardiac toxicity of adrenergic agents remain only partly defined, but recent findings have highlighted the 


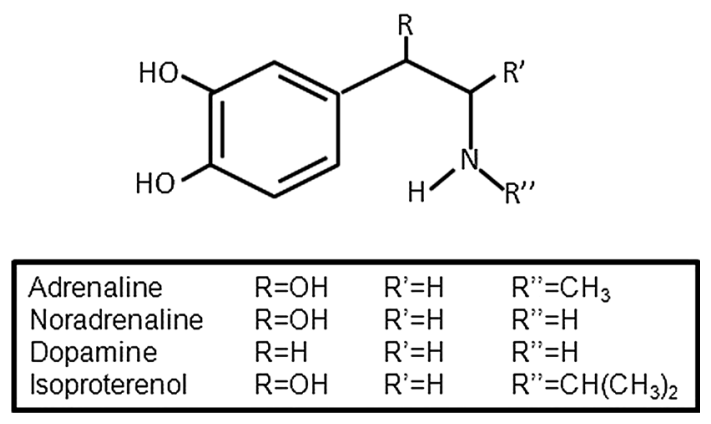

Fig. 1 Structure of the main catecholamines

crucial role played by altered redox status and mitochondrial dysfunction in such toxicity [6]. The purpose of the present article is to review the current state of knowledge on this topic. Besides catecholamines, a section will also be dedicated to cocaine, since this frequently used recreational drug also promotes significant cardiac toxicity, via mechanisms depending, in part, on its sympathomimetic actions.

\section{Catecholamines}

Major pharmacological aspects of catecholamines

Catecholamines, released from the adrenal medulla and from the central and sympathetic nervous system, function as hormones and neurotransmitters playing crucial regulatory roles in the cardiovascular system. Structurally, catecholamines include a dihydroxybenzene ring (catechol) and a nitrogen group (amine). They are generated from the aminoacid L-tyrosine through successive hydroxylation, decarboxylation and methylation steps resulting in the sequential formation of dihydroxyphenylalanine (L-Dopa), dopamine, norepinephrine (NE, noradrenaline) and epinephrine (Epi, adrenaline) [6, 7] (Fig. 1). The pharmacological actions and the cell responses to catecholamines are mediated by two major types ( $\alpha$ and $\beta$ ) of G proteinscoupled adrenergic receptors. The $\alpha$-adrenoceptors are further subdivided into $\alpha_{1}\left(\alpha_{1 \mathrm{~A}}, \alpha_{1 \mathrm{~B}}, \alpha_{1 \mathrm{D}}\right.$ subtypes) and $\alpha_{2}$ $\left(\alpha_{2 \mathrm{~A}}, \alpha_{2 \mathrm{~B}}\right.$ and $\alpha_{2 \mathrm{C}}$ subtypes) receptors, while the $\beta$ adrenoceptors comprise the $\beta_{1}, \beta_{2}$ and $\beta_{3}$ subtypes $[8,9]$.

The $\alpha_{1}$ receptors are coupled to pertussis-insensitive $G$ protein $\left(\mathrm{G}_{q / 11}\right)$ to activate phospholipase $\mathrm{C}$, promoting an increase in cytosolic $\mathrm{Ca}^{2+}\left(\left[\mathrm{Ca}^{2+}\right]_{i}\right)$ via the formation of diacylglycerol and inositol triphosphate [6]. In cardiac myocytes, $\alpha_{1 \mathrm{~A}}$ and $\alpha_{1 \mathrm{~B}}$ adrenoceptors mediate positive inotropic effects and hypertrophic responses, respectively, whereas in vascular smooth muscle cells, $\alpha_{1 \mathrm{D}}$ adrenoceptors elicit arterial vasoconstriction, notably in the coronary arteries $[6,10]$. The $\alpha_{2}$ receptors are coupled to inhibitory $\mathrm{G}$ proteins $\left(\mathrm{G}_{i}\right.$ and $\left.\mathrm{G}_{0}\right)$ and inhibit adenylyl cyclase signaling. They are essentially expressed at the nerve
Table 1 Affinity of the different adrenoceptors to endogenous and synthetic catecholamines and sympathomimetic agents

\begin{tabular}{lllllll}
\hline & $\alpha_{1}$ & $\alpha_{2}$ & $\beta_{1}$ & $\beta_{2}$ & $\beta_{3}$ & $\mathrm{DR}_{1-5}$ \\
\hline Adrenaline & +++ & +++ & ++++ & +++ & + & 0 \\
Noradrenaline & ++++ & +++ & +++ & + & + & 0 \\
Dopamine & ++ & $?$ & ++++ & ++ & $?$ & ++++ \\
Dobutamine & + & + & ++++ & ++ & 0 & 0 \\
Isoproterenol & - & - & +++ & +++ & + & 0 \\
Phenylephrine & ++++ & 0 & 0 & 0 & 0 & 0 \\
Ephedrine & +++ & +++ & ++ & ++ & $?$ & 0
\end{tabular}

Endogenous catecholamines are represented by adrenaline, noradrenaline and dopamine. Dobutamine and isoproterenol are synthetic catecholamines with predominant $\beta$-adrenergic actions. Phenylephrine is a sympathomimetic compound acting as a selective $\alpha_{1}$ agonist. Ephedrine is a synthetic sympathomimetic agent with mild direct $\beta$ agonist activity and with indirect $\alpha$-agonist activity produced by displacement of noradrenaline from nerve terminals. The table has been drawn from [10, 85-87]

$D R$ dopamine receptors

terminals from noradrenergic neurons, where they regulate neurotransmitter release via an inhibitory presynaptic feedback loop $[6,11]$. The $\beta_{1}$ and $\beta_{2}$ receptors activate a $\mathrm{G}_{s}$-adenylyl cyclase-cAMP-protein kinase A (PKA) cascade, leading to an increase in $\left[\mathrm{Ca}^{2+}\right]_{i}$. In the heart, this translates into positive inotropic, chronotropic, bathmotropic and lusitropic effects, resulting in an increase in heart rate, cardiac output, stroke work and cardiac relaxation (mainly mediated by $\beta_{1}$ receptors) $[6,12]$. In vascular smooth muscle, both $\beta_{1}$ and $\beta_{2}$ receptors mediate relaxant responses and vasodilation [13]. The $\beta 3$ receptors, expressed by cardiac myocytes, trigger a $\mathrm{G}_{i}-\mathrm{NO}-\mathrm{cGMP}$ pathway, which produces a negative effect on cardiac contractility [14]. Finally, in addition to $\alpha$ and $\beta$ adrenoceptors, five types of dopaminergic receptors exist $\left(D_{1-5}\right)$. $\mathrm{D}_{1}$ and $\mathrm{D}_{5}$ are coupled to $\mathrm{G}_{s}$ and activate adenylyl cyclase, whereas $\mathrm{D}_{2-4}$ inhibit adenylyl cyclase via $\mathrm{G}_{i}$ signaling. In the heart, only $\mathrm{D}_{1}$ and $\mathrm{D}_{4}$ are expressed, mediating some inotropic actions $[10,15]$. The affinity of catecholamines for the different receptors is indicated in Table 1.

The pharmacological actions of catecholamines are terminated by two major mechanisms, including reuptake (both presynaptic and extraneuronal) and metabolism [6]. The later depends primarily on oxidative deamination by neuronal mono-amine oxidase (MAO) to form dihydroxyphenylglycol, which is in turn $O$-methylated by extraneuronal catechol- $O$-methyl-transferase (COMT) into methoxhydroxyphenylglycol (MHPG). Catecholamines may also be first $O$-methylated into metanephrine and normetanephrine and secondarily deaminated into MHPG. MHPG is oxidized in the liver by alcohol and aldehyde dehydrogenases to form vanillylmandelic acid, the major 
end-product of norepinephrine and epinephrine metabolism, which is excreted in the urine [7].

\section{Catecholamine-induced cardiotoxicity}

Increased levels of endogenous catecholamines occur acutely to provide a short-term adaptation to stressful conditions, which is known as the fight-or-fly response [16]. Similarly, the exogenous administration of catecholamines is life-saving in clinical situations associated with reduced cardiac output and/or hypotension [17]. In contrast to these short-term benefits, sustained elevation of catecholamines is detrimental to the cardiovascular system by initiating significant cardiotoxicity [6], as observed in chronic heart failure [18], pheochromocytoma [19], stressinduced ("takotsubo") cardiomyopathy [20] and during prolonged therapy with high doses of exogenous catecholamines [1]. According to this last condition, the administration of the synthetic $\beta$-adrenoceptor agonist isoproterenol to laboratory animals has been used for decades as a well-recognized model of cardiac injury [21].

The morphological features of such injury, already described by Richard M. Pearce in the early twentieth century, reproduce many aspects of myocardial infarction [22]. They include various degrees of cardiomyocyte necrosis and apoptosis, myocardial infiltration with polymorphonuclear and mononuclear leukocytes, interstitial edema, subendocardial and subepicardial hemorrhages, and the progressive development of distinct foci of fibrosis over time $[6,21]$. On an ultrastructural viewpoint, the main alterations of catecholamine-induced cardiac toxicity comprise myofibrillar injury, mitochondrial swelling and dilatation of the sarcoplasmic reticulum [6,21].

Multiple mechanisms have been postulated to explain the cardiotoxicity of catecholamines. The overstimulation of catecholamine receptors enhances cardiac contractility and heart rate, with secondary increase in myocardial oxygen demand that may outweigh oxygen delivery, creating areas of "functional" hypoxia which can be exacerbated by vasoconstriction in the coronary macro- and micro-circulation and which reduce the supply of highenergy phosphates [6]. The later can be further aggravated by metabolic changes, such as the stimulation of lipolysis with deposition of neutral lipid droplets in cardiomyocytes [23], resulting in an uncoupling of oxidative phosphorylation [24]. Changes in membrane permeability leading to various electrolytic imbalances (hypokalemia, hypomagnesemia with reduced intracellular $\mathrm{Mg}^{2+}$ ) disturb multiple cellular homeostatic processes fostering additional myocardial toxicity [25].

Notwithstanding the aforementioned processes, there is now substantial evidence to incriminate intracellular calcium overload, oxidative stress and mitochondrial dysfunction as the major mechanisms accounting for the cardiotoxicity of catecholamines. A hallmark of sustained catecholamine exposure is a significant rise in $\mathrm{Ca}^{2+}$ both in the cytosol $\left(\left[\mathrm{Ca}^{2+}\right]_{i}\right)$ and mitochondria $\left(\left[\mathrm{Ca}^{2+}\right]_{m}\right)$ from cardiomyocytes, whose importance in triggering myocardial cell death has been identified more than 40 years ago by Fleckenstein and colleagues [26, 27]. The "Fleckenstein hypothesis" of $\mathrm{Ca}^{2+}$-mediated cardiotoxicity of catecholamines is nowadays described as the mitochondriocentric signal transducer-effector (MSTE) pathway: Mitochondrial $\mathrm{Ca}^{2+}$ overload (signal) triggers mitochondrial oxidative stress (transducer) and mitochondrial permeability transition (effector), eventually leading to cell death via apoptotic and necrotic pathways [28].

Myocardial $\left[\mathrm{Ca}^{2+}\right]_{i}$ and $\left[\mathrm{Ca}^{2+}\right]_{m}$ build up in response to $\beta$-adrenergic receptor-mediated activation of PKA, resulting in the downstream phosphorylation of multiple $\mathrm{Ca}^{2+}$ cycling proteins, including sarcolemmal L-type $\mathrm{Ca}^{2+}$ channels, phospholamban and sarcoplasmic reticulum ryanodine receptor $\mathrm{Ca}^{2+}$ release channels (RyR2) [16]. PKA-dependent phosphorylation of troponin and myosin binding protein $\mathrm{C}$ further participates to increase $\left[\mathrm{Ca}^{2+}\right]_{i}$, by reducing $\mathrm{Ca}^{2+}$ affinity of myofilaments $[6,16]$. Persistent activation of $\beta$-adrenoceptors also promotes the activation of $\mathrm{Ca} /$ calmodulin-dependent protein kinase II (CaMKII), both via PKA-dependent and PKA-independent mechanisms [29]. Activated CaMKII phosphorylates multiple protein targets, which comprise voltage-gated $\mathrm{Ca}^{2+}$ channels, RyR2 $\mathrm{Ca}^{2+}$ release channels and voltagegated $\mathrm{Na}^{+}$channels, with resulting increase in $\left[\mathrm{Ca}^{2+}\right]_{i}$ [30]. Following the rise in $\left[\mathrm{Ca}^{2+}\right]_{i}$, a progressive increase in $\left[\mathrm{Ca}^{2+}\right]_{m}$ occurs, leading to a rapid change in the permeability of the inner mitochondrial membrane, followed by swelling of the mitochondrial matrix, loss of respiratory control and generation of reactive oxygen species (ROS) which further exacerbates the $\mathrm{Ca}^{2+}$-induced mitochondrial dysfunction [28].

The pathophysiological events triggered by elevated $\left[\mathrm{Ca}^{2+}\right]_{m}$ are considerably amplified by the oxidative stress that develops upon sustained exposure to high levels of catecholamines, in connection with the following identified mechanisms. First, MAO-dependent oxidative deamination of catecholamines forms hydrogen peroxide $\left(\mathrm{H}_{2} \mathrm{O}_{2}\right)$, which may be converted to the highly reactive hydroxyl radical $(\mathrm{OH})$ through metal catalysis (Fenton chemistry) [6]. Secondly, activation of $\alpha_{1}$-adrenoceptors by catecholamines induces the activation of NADPH oxidase, with ensuing generation of the superoxide anion radical $\left(\mathrm{O}_{2}^{-}\right)$in cardiac myocytes [31]. Third, and most importantly, catecholamines are readily oxidized into toxic compounds termed "aminochromes" (due to their colored appearance in solution) [24]. This process occurs spontaneously at a low rate (autooxidation), but it is markedly accelerated in 
Fig. 2 Structure of aminochromes formed from the oxidation of catecholamines
Adrenochrome<smiles>CN1C2=CC(=O)C(=O)C=C2C1O</smiles>

Noradrenochrome<smiles>O=C1C=C2NCC(O)C2=CC1=O</smiles>

Dopachrome<smiles>O=C1C=C2CCNC2=CC1=O</smiles>

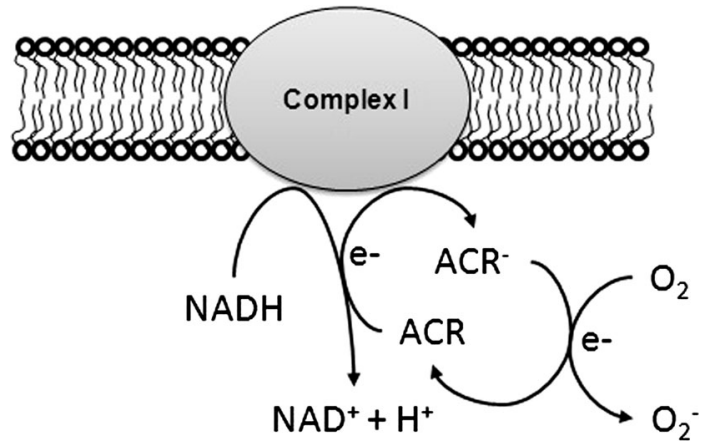

Fig. 3 Formation of superoxide via redox cycling of aminochromes. Aminochromes (ACR) are reduced to aminochrome semiquinones $\left(\mathrm{ACR}^{-}\right)$in the presence of $\mathrm{NADH}$ by complex $\mathrm{I}$ in the inner mitochondrial membrane. Auto-oxidation of $\mathrm{ACR}^{-}$back to ACR induces the generation of the superoxide anion radical $\left(\mathrm{O}_{2}^{-}\right)$. The transfer of electrons is indicated by $\mathrm{e}^{-}$

the presence of oxidants and free radicals such as $\mathrm{O}_{2}^{--}$, redox metals (especially iron and copper) and by enzymatic catalysis (notably by xanthine oxidase, myeloperoxidase and cytochrome oxidase) [24, 32-34]. Catecholamine oxidation is a two-electron process forming ortho-quinone derivatives, followed by cyclization into leukoaminochromes which are further oxidized into aminochromes [32], whose chemical structure is indicated in Fig. 2.

Aminochromes exert direct toxic effects on the coronary arteries (vasoconstriction) and the myocardium, including inhibition of oxidative phosphorylation and depression of calcium binding, with the overall result to reduce contractile force and to produce extensive necrotic damage, as shown in both ex vivo [35-37] and in vivo [38] experimental models. Besides their direct toxicity, aminochromes also induce the formation of large amounts of ROS via redox cycling processes occurring primarily in mitochondria [39]. The first step of this cycle is the one-electron reduction to aminochrome semiquinone in the presence of $\mathrm{NADH}$, catalyzed by complex I from the respiratory chain $[39,40]$. In the second step, the semiquinone immediately regenerates the native aminochrome by auto-oxidation in the presence of oxygen, releasing one molecule of $\mathrm{O}_{2}^{-}$ (Fig. 3). The cycle is then renewed, promoting an explosive enhancement of $\mathrm{O}_{2}^{--}$generation, which, in turn, triggers the further oxidation of catecholamines within their respective aminochromes, whose concentrations is thereby exponentially increasing [39].

When the formation of free radicals and oxidants outweighs the endogenous antioxidant capacities, a state of oxidative stress develops with profound cytotoxic consequences related to oxidative damage in lipids, proteins and nucleic acids [41, 42]. The "oxidative stress theory" of catecholamine cardiotoxicity is supported by a myriad of studies showing considerable benefit of antioxidant therapies, including melatonin [43], quercetin [44], ascorbic acid [45] or $N$-acetylcysteine [46], to name only a few. It is particularly noticeable that the oxidative stress elicited by catecholamines, in conjunction with the marked $\left[\mathrm{Ca}^{2+}\right]_{i}$ and $\left[\mathrm{Ca}^{2+}\right]_{m}$ overload, fosters the opening of the mitochondrial permeability transition pore (mPTP) in cardiac myocytes, as recently well demonstrated in a model of isoproterenol-induced cardiac injury [47]. Opening of the mPTP promotes mitochondrial depolarization and cessation of oxygen transport. This triggers the secondary generation of free radicals, a process termed "ROS-induced ROS release" (RIRR), which amplifies mitochondrial oxidative stress and mPTP opening, leading to permeabilization of the outer mitochondrial membrane and efflux of pro-apoptotic molecules $[48,49]$. Depending on the degree of mPTP opening, cells may either recover (minimal opening) or die by apoptosis (moderate opening) or necrosis (massive, irreversible opening) [50, 51].

In summary, a sustained high level of catecholamine can exert major toxic effects on the myocardium, leading to morphological alterations similar to those produced by myocardial infarction, including primarily cardiomyocyte cell death and progressive focal myocardial fibrosis. Such toxicity stems from a multiplicity of catecholamines' actions on the heart, most significantly calcium overload, oxidative stress and mitochondrial dysfunction, as illustrated in Fig. 4.

\section{Cocaine}

Pharmacological basis of cocaine effects

Cocaine (benzoylmethylecgonine), derived from the leaves of Erythroxylon coca, is a commonly used illicit drug with 
Fig. 4 Mechanisms of catecholamine-induced cardiotoxicity. The major pathways of cardiotoxicity are indicated with the black arrows

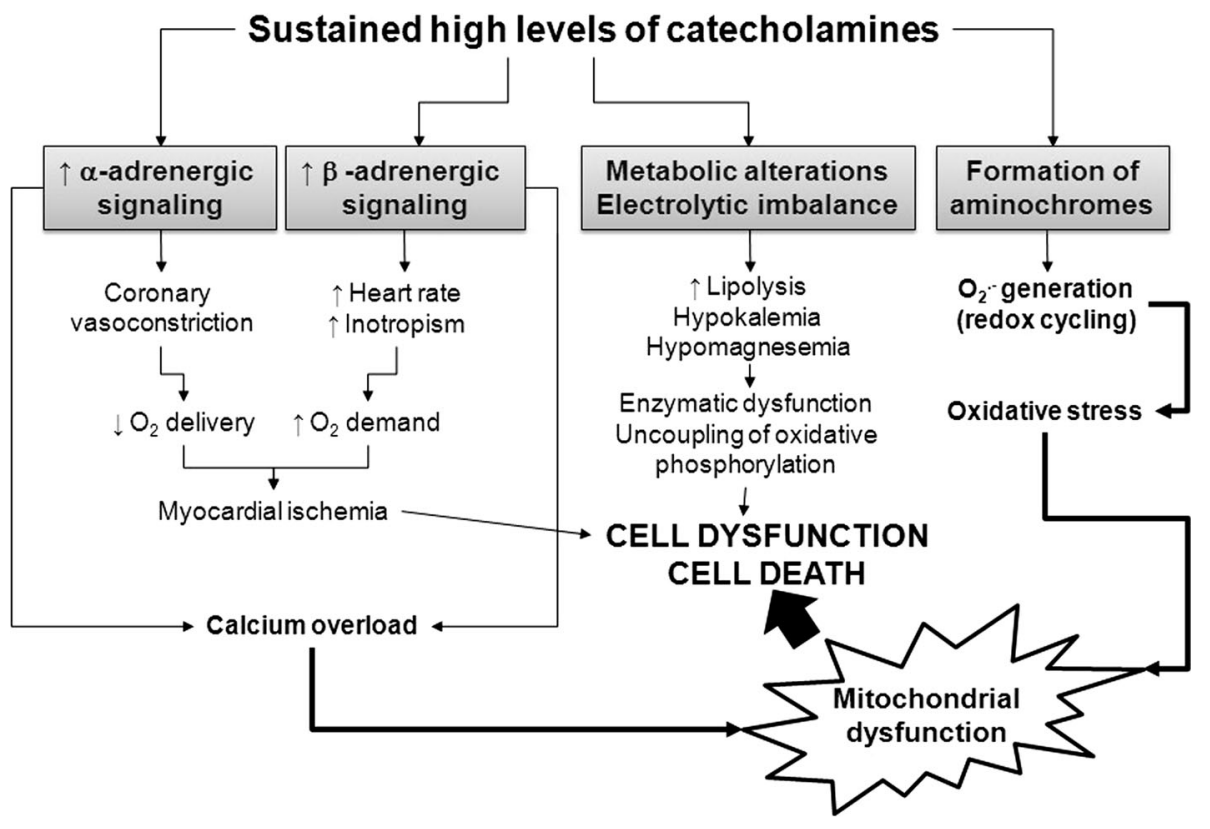

potent stimulant actions. It is generally used by nasal insufflation or by inhalation ("crack"), reaching peak plasma concentrations after 30-60 min or within seconds to minutes, respectively. Its serum half-life is about $60 \mathrm{~min}$, being rapidly cleared via tissue uptake and metabolism by plasma and liver esterases into two major water-soluble active metabolites, benzoylecgonine and ecgonine methylester, excreted in the urine $[52,53]$. The effects of cocaine are related to the blockade of the presynaptic reuptake of dopamine and norepinephrine, with resulting increase in their concentration in the synaptic cleft and enhanced postsynaptic transmission, as well as enhanced central sympathetic outflow [54, 55]. The psychostimulant actions of cocaine mainly result from enhanced dopamine neurotransmission, whereas the cardiovascular effects of the drug are related primarily to its sympathomimetic actions. In addition, cocaine also blocks the fast $\mathrm{Na}^{+}$channels in membranes, reducing the phase 0 of the action-potential, thereby inducing a local anesthetic effect $[56,57]$.

Cardiovascular consequences associated with cocaine use

Cocaine use is associated with numerous acute and chronic cardiovascular complications, which comprise chest pain, hypertension, acute myocardial infarction, arrhythmias, sudden death, aortic dissection, stroke (both ischemic and hemorrhagic) and cardiomyopathy leading to chronic heart failure $[53,55]$. The primary mechanism of cocaine's cardiovascular toxicity relates to its marked sympathomimetic effect. Increased $\alpha_{1}$-adrenergic stimulation promotes arterial vasoconstriction with subsequent elevation of blood pressure and reduced microvascular blood flows, whereas enhanced $\beta$-adrenergic stimulation increases heart rate and cardiac contractility [54]. The vasoconstrictive action of cocaine is further amplified by two additional properties, namely inhibition of nitric oxide synthesis [58] and increased formation of endothelin-1 [59] by the endothelium. Furthermore, cocaine induces a prothrombotic state by activating platelets (via elevated P-selectin expression, increased release of platelet factor 4 , thromboglobulin, NAP-2 and CD40 ligand) [60] and coagulation (via an increase in plasminogen-activator inhibitor, fibrinogen and tissue factor, together with decreased expression of tissue factor inhibitor, antithrombin and protein C) [56, $61,62]$. Over time, these various effects promote accelerated atherosclerosis and endothelial dysfunction, which further increase the risk of cardiovascular events (notably myocardial infarction and ischemic stroke) in cocaine users [55].

The significant increase in blood pressure due to $\alpha_{1^{-}}$ adrenergic-dependent vasoconstriction is the major mechanism responsible for acute complications such as cerebral hemorrhage and aortic dissection in cocaine users [53, 55]. The $\alpha_{1}$-mediated coronary vasoconstriction, together with the $\beta_{1}$-adrenergic-induced tachycardia and increased contractility, leads to an imbalance between myocardial oxygen demand and supply, triggering myocardial ischemia and acute myocardial infarction $[53,55]$, the risk of which being increased 24-fold in the $60 \mathrm{~min}$ following cocaine use [63]. Importantly, coronary vasoconstriction may initially resolve when serum cocaine concentration decreases, but may backslide after several hours due to the effects of cocaine metabolites, producing recurrent, delayed 
myocardial ischemia $[53,55]$. Coronary thrombus formation due to platelet activation is an additional factor that may precipitate myocardial infarction [57]. Cocaine can further promote major arrhythmias and sudden cardiac death, both via its sympathomimetic effects (increased ventricular irritability) and its blocking effects on $\mathrm{Na}^{+}$ channels, which prolongs QRS duration and QT interval and favors the development of reentrant circuits, similarly to class I antiarrhythmic agents $[53,55,57]$.

In the long term, chronic use of cocaine may result in a particular form of cardiomyopathy with various degrees of systolic and diastolic dysfunction, cardiac hypertrophy and dilatation, resulting in chronic heart failure [53, 55]. Histological characteristics include loss of myofibrils, multiple foci of contraction band necrosis, fibrosis and interstitial infiltrates with inflammatory cells [57, 64], which are similar to the cardiac lesions described following sustained catecholamine exposure (for instance, during pheochromocytoma) [55]. In a limited number of cases, evidence of inflammatory myocarditis has been noted, characterized by perivascular eosinophilic infiltrates and absence of necrosis, attributed to an hypersensitivity reaction to cocaine itself or any contaminants added to adulterate the drug, such as amphetamine, sugars or talc [57].

Role of oxidative stress and mitochondrial dysfunction in cocaine cardiotoxicity

Recent observations support a key role of myocardial oxidative stress and mitochondrial dysfunction in the pathogenesis of cocaine-induced cardiomyopathy [65-67]. Indeed, substantial evidence of cardiac oxidative damage, including depletion of antioxidants and lipid peroxidation, has been obtained both in laboratory animals $[65,66,68]$ and humans $[69,70]$ exposed to cocaine. Underlying mechanisms include (1) indirect, catecholamine-induced, oxidative stress, due to formation of aminochromes and redox cycling compounds (see above), (2) the activation of the $\mathrm{O}_{2}^{--}$-generating enzymes NADPH oxidase [65, 66, 71, 72] and xanthine oxidase [73], (3) the induced formation of ROS by dysfunctional mitochondria $[67,73,74]$ and (4) the generation of pro-oxidant derivatives of cocaine metabolites [74, 75].

Activation of NADPH oxidase (Nox) by cocaine in cardiac myocytes has been linked with an $\alpha_{1}$-adrenergic-G protein-PKC-coupled mechanism, leading to phosphorylation of the $\mathrm{p} 47^{\text {phox }}$ cytosolic subunit of the enzyme [71]. The dependence on $\alpha_{1}$-adrenoceptor was notably demonstrated by the abrogation of Nox activation in the heart of cocaine-treated rats after administration of the $\alpha_{1}$ antagonist prazosin [71]. Fan and co-workers then demonstrated that cocaine could also activate Nox in rat myocardium via PKC-dependent but $\alpha_{1}$-independent upregulation of the expression of Nox-2, one of the two Nox isoforms (with
Nox4) present in cardiac tissue [72]. The activation of Nox appears to be a critical event for the propagation of ROS generation in hearts exposed to cocaine, as supported by Isabelle et al. [65]. These investigators found, in a model of chronic cocaine administration to rats, that $\mathrm{O}_{2}^{--}$formed in response to Nox activation induced the secondary activation of xanthine oxidase (XO) [76], leading to further $\mathrm{O}_{2}^{-}$ formation, which initiates a cycle of progressive amplification of oxidative stress [65]. In addition, the intense generation of $\mathrm{O}_{2}^{--}$by co-activation of Nox and XO targets mitochondria to produce additional ROS via the RIRR mechanims (ROS-induced ROS release) [49], contributing to this amplification cycle [73].

An additional pathway of cocaine-mediated oxidative stress which has received little attention may be related to the formation of oxidative metabolites [75]. Besides the major degradation pathway of cocaine by ester hydrolysis, a minor $N$-oxidative pathway process also exists, in which cocaine is demethylated to norcocaine, and then oxidized to $N$-hydroxynorcocaine and norcocaine nitroxide [77, 78]. Evidence has been obtained that $N$-hydroxynorcocaine and norcocaine nitroxide form a couple transferring electrons from NADPH and generating $\mathrm{O}_{2}^{--}$during redox cycling, a mechanism notably incriminated in the liver toxicity elicited by cocaine $[77,79]$. In addition to promote ROS formation, these oxidized metabolites of cocaine have also been associated with direct toxic effects on mitochondria, by suppressing state 3 and 4 respiration, resulting in suppression of ATP generation [74].

The primary target of cocaine-mediated oxidative stress is the mitochondria, with various established consequences, including formation of ROS (see above), impaired electron transfer and suppression of ATP production [67, 73, 74], as well as membrane permeabilization with release of cytochrome $\mathrm{C}$ and subsequent cell death [80-82]. The mitochondrial impairment elicited by cocaine has been particularly well addressed in a recent work by Vergeade et al. [67]. In this study, the administration of cocaine for seven consecutive days to rats resulted in significant left ventricular dysfunction. At the cellular level, cocaine led to an increase in oxygen consumption in cardiac fibers together with increased ROS generation and decreased ATP synthesis, indicative of an uncoupling of oxidative phosphorylation. The changes were selectively noted in the interfibrillar fraction, but not the subsarcolemmal fraction of mitochondria, pointing to differential susceptibility of distinct mitochondrial fractions to pathological stimuli. Cotreatment with cocaine and MitoQ, a mitochondrial-targeted antioxidant [83, 84], suppressed these mitochondrial abnormalities and completely prevented cardiac dysfunction, thereby providing strong support to the role of a mitochondrial defect in cocaine-mediated cardiotoxicity [67]. 
Fig. 5 Major mechanisms of cocaine toxicity in the cardiovascular system. $B P$ blood pressure, $H R$ heart rate, NOX NADPH oxidase, $X O$ xanthine oxidase

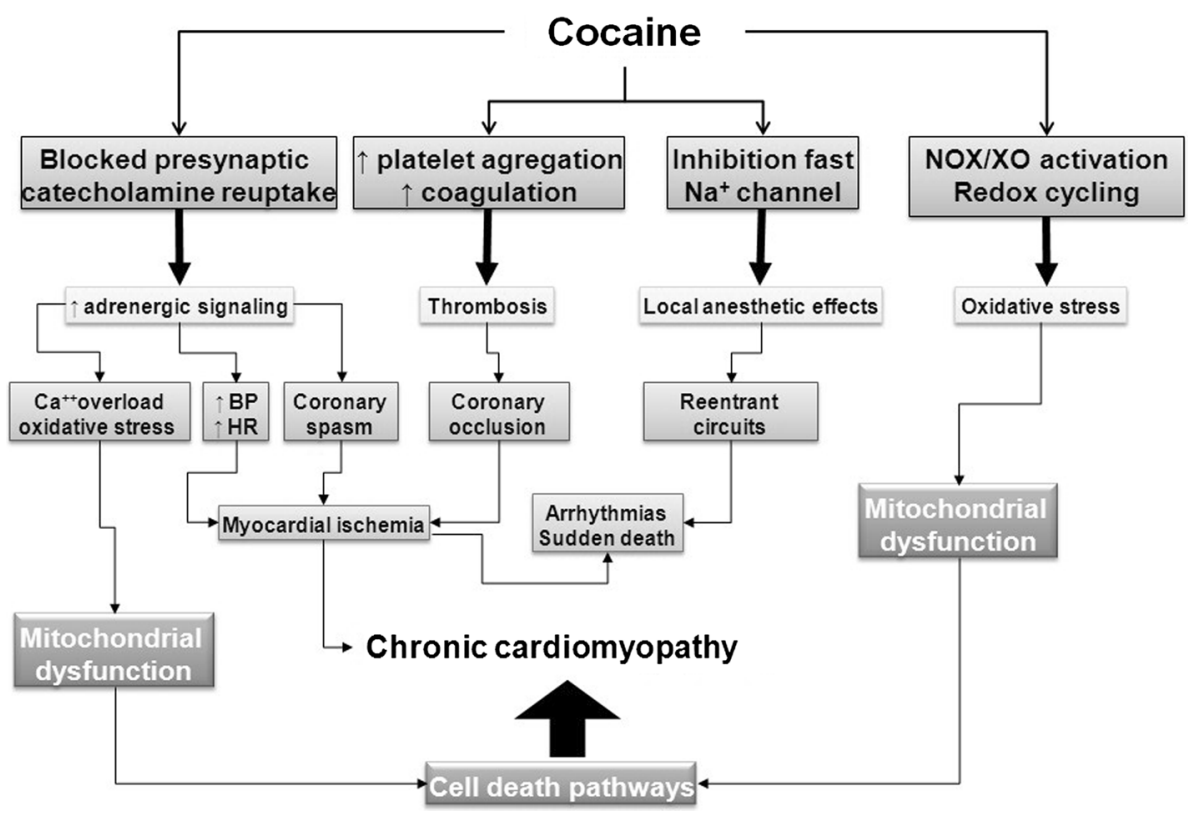

Figure 5 summarizes the mechanisms involved in cardiovascular toxicity associated with cocaine use. Besides its considerable sympathomimetic effects resulting in catecholamine-mediated adverse actions, cocaine also fosters the generation of significant amounts of ROS within cardiomyocytes, whose major consequence is mitochondrial dysfunction with subsequent activation of cell death processes.

\section{Conclusions}

Although catecholamines are essential to support life in conditions of acute cardiovascular failure, sustained adrenergic stimulation exposes to the risk of significant cardiotoxicity. In addition to the direct role of sustained stimulation of adrenoceptors, catecholamines promote profound mitochondrial dysfunction in cardiac myocytes by inducing intracellular calcium overload and, most importantly, by initiating mitochondrial oxidative stress following their transformation into toxic aminochromes. Mitochondria also play a central role in the cardiac toxicity of cocaine, which acts, partly, through its sympathomimetic actions, but also through its ability to disturb redox balance in cardiac myocytes. Clinicians should be aware of these dangerous side effects in order to prevent the detrimental consequences of hyperadrenergic stress, notably by a cautious use of exogenous catecholamines. Furthermore, future studies should evaluate whether antioxidant molecules efficacious in laboratory animals, such as the recently developed mitochondrial-targeted antioxidants, can protect the heart from the toxicity of catecholamines and cocaine in the clinical setting.

Acknowledgments This work was supported, in part, by a grant from the Swiss National Fund for Scientific Research (No. 320000/118174) to LL and by the Intramural Program of the NIH/ NIAAA to PP.

Conflict of interest Drs. Lucas LIAUDET, Belinda CALDERARI and Pal PACHER have no conflicts of interest or financial ties to disclose with respect to this work.

\section{References}

1. Dunser MW, Hasibeder WR (2009) Sympathetic overstimulation during critical illness: adverse effects of adrenergic stress. J Intensive Care Med 24:293-316

2. Lymperopoulos A, Rengo G, Koch WJ (2013) Adrenergic nervous system in heart failure: pathophysiology and therapy. Circ Res 113:739-753

3. Tacon CL, McCaffrey J, Delaney A (2012) Dobutamine for patients with severe heart failure: a systematic review and metaanalysis of randomised controlled trials. Intensive Care Med 38:359-367

4. Mebazaa A, Parissis J, Porcher R, Gayat E, Nikolaou M, Boas FV, Delgado JF, Follath F (2011) Short-term survival by treatment among patients hospitalized with acute heart failure: the global ALARM-HF registry using propensity scoring methods. Intensive Care Med 37:290-301

5. Schmittinger CA, Torgersen C, Luckner G, Schroder DC, Lorenz I, Dunser MW (2012) Adverse cardiac events during catecholamine vasopressor therapy: a prospective observational study. Intensive Care Med 38:950-958

6. Costa VM, Carvalho F, Bastos ML, Carvalho RA, Carvalho M, Remiao F (2011) Contribution of catecholamine reactive intermediates and oxidative stress to the pathologic features of heart diseases. Curr Med Chem 18:2272-2314 
7. Eisenhofer G, Kopin IJ, Goldstein DS (2004) Catecholamine metabolism: a contemporary view with implications for physiology and medicine. Pharmacol Rev 56:331-349

8. Alexander SP, Mathie A, Peters JA (2011) Guide to receptors and channels (GRAC), 5th edition. Br J Pharmacol 164(Suppl 1):S1S324

9. Molinoff PB (1984) $\alpha$ - and $\beta$-adrenergic receptor subtypes properties, distribution and regulation. Drugs 28(Suppl 2):1-15

10. Bangash MN, Kong ML, Pearse RM (2012) Use of inotropes and vasopressor agents in critically ill patients. $\mathrm{Br} \mathrm{J}$ Pharmacol 165:2015-2033

11. Philipp M, Brede M, Hein L (2002) Physiological significance of $\alpha(2)$-adrenergic receptor subtype diversity: one receptor is not enough. Am J Physiol Regul Integr Comp Physiol 283:R287R295

12. Fu Y, Xiao H, Zhang Y (2012) $\beta$-adrenoceptor signaling pathways mediate cardiac pathological remodeling. Front Biosci (Elite Ed) 4:1625-1637

13. Chruscinski A, Brede ME, Meinel L, Lohse MJ, Kobilka BK, Hein L (2001) Differential distribution of $\beta$-adrenergic receptor subtypes in blood vessels of knockout mice lacking $\beta(1)$ - or $\beta(2)$ adrenergic receptors. Mol Pharmacol 60:955-962

14. Gauthier C, Langin D, Balligand JL (2000) $\beta 3$-adrenoceptors in the cardiovascular system. Trends Pharmacol Sci 21:426-431

15. Missale C, Nash SR, Robinson SW, Jaber M, Caron MG (1998) Dopamine receptors: from structure to function. Physiol Rev 78:189-225

16. Bers DM, Despa S (2009) Na/K-ATPase-an integral player in the adrenergic fight-or-flight response. Trends Cardiovasc Med 19:111-118

17. Hollenberg SM (2011) Vasoactive drugs in circulatory shock. Am J Respir Crit Care Med 183:847-855

18. Floras JS (2009) Sympathetic nervous system activation in human heart failure: clinical implications of an updated model. J Am Coll Cardiol 54:375-385

19. Nanda AS, Feldman A, Liang CS (1995) Acute reversal of pheochromocytoma-induced catecholamine cardiomyopathy. Clin Cardiol 18:421-423

20. Nef HM, Mollmann H, Akashi YJ, Hamm CW (2010) Mechanisms of stress (Takotsubo) cardiomyopathy. Nat Rev Cardiol 7:187-193

21. Rona G (1985) Catecholamine cardiotoxicity. J Mol Cell Cardiol 17:291-306

22. Pearce RM (1906) Experimental myocarditis: a study of the histological changes following intravenous injections of adrenalin. J Exp Med 8:400-409

23. Jodalen H, Neely JR (1991) Lipid accumulation in the perfused rat heart after isoproterenol administration. Acta Physiol Scand Suppl 599:93-97

24. Behonick GS, Novak MJ, Nealley EW, Baskin SI (2001) Toxicology update: the cardiotoxicity of the oxidative stress metabolites of catecholamines (aminochromes). J Appl Toxicol 21(Suppl 1):S15-S22

25. Borkowski BJ, Cheema Y, Shahbaz AU, Bhattacharya SK, Weber KT (2011) Cation dyshomeostasis and cardiomyocyte necrosis: the Fleckenstein hypothesis revisited. Eur Heart J 32:1846-1853

26. Fleckenstein A, Janke J, Doring HJ, Leder O (1974) Myocardial fiber necrosis due to intracellular Ca overload-a new principle in cardiac pathophysiology. Recent Adv Stud Cardiac Struct Metab 4:563-580

27. Fleckenstein A, Kanke J, Doring HJ, Leder O (1975) Key role of $\mathrm{Ca}$ in the production of noncoronarogenic myocardial necroses. Recent Adv Stud Cardiac Struct Metab 6:21-32

28. Khan MU, Cheema Y, Shahbaz AU, Ahokas RA, Sun Y, Gerling IC, Bhattacharya SK, Weber KT (2012) Mitochondria play a central role in nonischemic cardiomyocyte necrosis: common to acute and chronic stressor states. Pflugers Archiv: Eur J Physiol 464:123-131

29. Zhang X, Szeto C, Gao E, Tang M, Jin J, Fu Q, Makarewich C, Ai X, Li Y, Tang A, Wang J, Gao H, Wang F, Ge XJ, Kunapuli SP, Zhou L, Zeng C, Xiang KY, Chen X (2013) Cardiotoxic and cardioprotective features of chronic $\beta$-adrenergic signaling. Circ Res 112:498-509

30. Swaminathan PD, Purohit A, Hund TJ, Anderson ME (2012) Calmodulin-dependent protein kinase II: linking heart failure and arrhythmias. Circ Res 110:1661-1677

31. Amin JK, Xiao L, Pimental DR, Pagano PJ, Singh K, Sawyer DB, Colucci WS (2001) Reactive oxygen species mediate $\alpha$-adrenergic receptor-stimulated hypertrophy in adult rat ventricular myocytes. J Mol Cell Cardiol 33:131-139

32. Remiao F, Milhazes N, Borges F, Carvalho F, Bastos ML, LemosAmado F, Domingues P, Ferrer-Correia A (2003) Synthesis and analysis of aminochromes by HPLC-photodiode array. Adrenochrome evaluation in rat blood. Biomed Chromatogr 17:6-13

33. Haskova P, Kovarikova P, Koubkova L, Vavrova A, Mackova E, Simunek T (2011) Iron chelation with salicylaldehyde isonicotinoyl hydrazone protects against catecholamine autoxidation and cardiotoxicity. Free Radic Biol Med 50:537-549

34. Remiao F, Carmo H, Carvalho F, Bastos ML (2001) Copper enhances isoproterenol toxicity in isolated rat cardiomyocytes: effects on oxidative stress. Cardiovasc Toxicol 1:195-204

35. Taam GM, Takeo S, Ziegelhoffer A, Singal PK, Beamish RE, Dhalla NS (1986) Effect of adrenochrome on adenine nucleotides and mitochondrial oxidative phosphorylation in rat heart. Can $\mathbf{J}$ Cardiol 2:88-93

36. Yates JC, Beamish RE, Dhalla NS (1981) Ventricular dysfunction and necrosis produced by adrenochrome metabolite of epinephrine: relation to pathogenesis of catecholamine cardiomyopathy. Am Heart J 102:210-221

37. Yates JC, Taam GM, Singal PK, Beamish RE, Dhalla NS (1980) Protection against adrenochrome-induced myocardial damage by various pharmacological interventions. $\mathrm{Br} \quad \mathrm{J}$ Exp Pathol 61:242-255

38. Karmazyn M, Beamish RE, Fliegel L, Dhalla NS (1981) Adrenochrome-induced coronary artery constriction in the rat heart. J Pharmacol Exp Ther 219:225-230

39. Bindoli A, Deeble DJ, Rigobello MP, Galzigna L (1990) Direct and respiratory chain-mediated redox cycling of adrenochrome. Biochim Biophys Acta 1016:349-356

40. Genova ML, Abd-Elsalam NM, Mahdy el SM, Bernacchia A, Lucarini M, Pedulli GF, Lenaz G (2006) Redox cycling of adrenaline and adrenochrome catalysed by mitochondrial complex I. Arch Biochem Biophys 447:167-173

41. Liaudet L, Vassalli G, Pacher P (2009) Role of peroxynitrite in the redox regulation of cell signal transduction pathways. Front Biosci 14:4809-4814

42. Pacher P, Beckman JS, Liaudet L (2007) Nitric oxide and peroxynitrite in health and disease. Physiol Rev 87:315-424

43. Patel V, Upaganlawar A, Zalawadia R, Balaraman R (2010) Cardioprotective effect of melatonin against isoproterenol induced myocardial infarction in rats: a biochemical, electrocardiographic and histoarchitectural evaluation. Eur J Pharmacol 644:160-168

44. Panda S, Kar A, Banerjee T, Sharma N (2012) Combined effects of quercetin and atenolol in reducing isoproterenol-induced cardiotoxicity in rats: possible mediation through scavenging free radicals. Cardiovasc Toxicol 12:235-242

45. Buttros JB, Bergamaschi CT, Ribeiro DA, Fracalossi AC, Campos RR (2009) Cardioprotective actions of ascorbic acid during isoproterenol-induced acute myocardial infarction in rats. Pharmacology 84:29-37 
46. Nagoor Meeran MF, Stanely Mainzen Prince P, Hidhayath Basha R (2012) Preventive effects of $N$-acetyl cysteine on lipids, lipoproteins and myocardial infarct size in isoproterenol induced myocardial infarcted rats: an in vivo and in vitro study. Eur $\mathbf{J}$ Pharmacol 677:116-122

47. Izem-Meziane M, Djerdjouri B, Rimbaud S, Caffin F, Fortin D, Garnier A, Veksler V, Joubert F, Ventura-Clapier R (2012) Catecholamine-induced cardiac mitochondrial dysfunction and mPTP opening: protective effect of curcumin. Am J Physiol Heart Circ Physiol 302:H665-H674

48. Biary N, Xie C, Kauffman J, Akar FG (2011) Biophysical properties and functional consequences of reactive oxygen species (ROS)-induced ROS release in intact myocardium. J Physiol 589:5167-5179

49. Zorov DB, Filburn CR, Klotz LO, Zweier JL, Sollott SJ (2000) Reactive oxygen species (ROS)-induced ROS release: a new phenomenon accompanying induction of the mitochondrial permeability transition in cardiac myocytes. J Exp Med 192:1001-1014

50. Halestrap AP (2009) What is the mitochondrial permeability transition pore? J Mol Cell Cardiol 46:821-831

51. Brenner C, Moulin M (2012) Physiological roles of the permeability transition pore. Circ Res 111:1237-1247

52. Phillips K, Luk A, Soor GS, Abraham JR, Leong S, Butany J (2009) Cocaine cardiotoxicity: a review of the pathophysiology, pathology, and treatment options. Am J Cardiovasc Drugs 9:177-196

53. Schwartz BG, Rezkalla S, Kloner RA (2010) Cardiovascular effects of cocaine. Circulation 122:2558-2569

54. Kloner RA, Rezkalla SH (2003) Cocaine and the heart. N Engl J Med 348:487-488

55. Lange RA, Hillis LD (2001) Cardiovascular complications of cocaine use. N Engl J Med 345:351-358

56. Lippi G, Plebani M, Cervellin G (2010) Cocaine in acute myocardial infarction. Adv Clin Chem 51:53-70

57. Rump AF, Theisohn M, Klaus W (1995) The pathophysiology of cocaine cardiotoxicity. Forensic Sci Int 71:103-115

58. Pradhan L, Mondal D, Chandra S, Ali M, Agrawal KC (2008) Molecular analysis of cocaine-induced endothelial dysfunction: role of endothelin-1 and nitric oxide. Cardiovasc Toxicol 8:161-171

59. Wilbert-Lampen U, Seliger C, Zilker T, Arendt RM (1998) Cocaine increases the endothelial release of immunoreactive endothelin and its concentrations in human plasma and urine: reversal by coincubation with sigma-receptor antagonists. Circulation 98:385-390

60. Pereira J, Saez CG, Pallavicini J, Panes O, Pereira-Flores K, Cabreras MJ, Massardo T, Mezzano D (2011) Platelet activation in chronic cocaine users: effect of short term abstinence. Platelets 22:596-601

61. Steffel J, Iseli S, Arnet C, Luscher TF, Tanner FC (2006) Cocaine unbalances endothelial tissue factor and tissue factor pathway inhibitor expression. J Mol Cell Cardiol 40:746-749

62. Moliterno DJ, Lange RA, Gerard RD, Willard JE, Lackner C, Hillis LD (1994) Influence of intranasal cocaine on plasma constituents associated with endogenous thrombosis and thrombolysis. Am J Med 96:492-496

63. Mittleman MA, Mintzer D, Maclure M, Tofler GH, Sherwood JB, Muller JE (1999) Triggering of myocardial infarction by cocaine. Circulation 99:2737-2741

64. Tazelaar HD, Karch SB, Stephens BG, Billingham ME (1987) Cocaine and the heart. Hum Pathol 18:195-199

65. Isabelle M, Vergeade A, Moritz F, Dautreaux B, Henry JP, Lallemand F, Richard V, Mulder P, Thuillez C, Monteil C (2007) NADPH oxidase inhibition prevents cocaine-induced up-regulation of xanthine oxidoreductase and cardiac dysfunction. J Mol Cell Cardiol 42:326-332
66. Moritz F, Monteil C, Isabelle M, Bauer F, Renet S, Mulder P, Richard V, Thuillez C (2003) Role of reactive oxygen species in cocaine-induced cardiac dysfunction. Cardiovasc Res 59:834-843

67. Vergeade A, Mulder P, Vendeville-Dehaudt C, Estour F, Fortin D, Ventura-Clapier R, Thuillez C, Monteil C (2010) Mitochondrial impairment contributes to cocaine-induced cardiac dysfunction: Prevention by the targeted antioxidant MitoQ. Free Radic Biol Med 49:748-756

68. Pacifici R, Fiaschi AI, Micheli L, Centini F, Giorgi G, Zuccaro P, Pichini S, Di Carlo S, Bacosi A, Cerretani D (2003) Immunosuppression and oxidative stress induced by acute and chronic exposure to cocaine in rat. Int Immunopharmacol 3:581-592

69. Afonso L, Mohammad T, Thatai D (2007) Crack whips the heart: a review of the cardiovascular toxicity of cocaine. Am J Cardiol 100:1040-1043

70. Darke S, Kaye S, Duflou J (2006) Comparative cardiac pathology among deaths due to cocaine toxicity, opioid toxicity and nondrug-related causes. Addiction 101:1771-1777

71. Isabelle M, Monteil C, Moritz F, Dautreaux B, Henry JP, Richard V, Mulder P, Thuillez C (2005) Role of $\alpha 1$-adrenoreceptors in cocaine-induced NADPH oxidase expression and cardiac dysfunction. Cardiovasc Res 67:699-704

72. Fan L, Sawbridge D, George V, Teng L, Bailey A, Kitchen I, Li JM (2009) Chronic cocaine-induced cardiac oxidative stress and mitogen-activated protein kinase activation: the role of Nox2 oxidase. J Pharmacol Exp Ther 328:99-106

73. Vergeade A, Mulder P, Vendeville C, Ventura-Clapier R, Thuillez C, Monteil C (2012) Xanthine oxidase contributes to mitochondrial ROS generation in an experimental model of cocaine-induced diastolic dysfunction. J Cardiovasc Pharmacol 60:538-543

74. Boess F, Ndikum-Moffor FM, Boelsterli UA, Roberts SM (2000) Effects of cocaine and its oxidative metabolites on mitochondrial respiration and generation of reactive oxygen species. Biochem Pharmacol 60:615-623

75. Kovacic P (2005) Role of oxidative metabolites of cocaine in toxicity and addiction: oxidative stress and electron transfer. Med Hypotheses 64:350-356

76. Pacher P, Nivorozhkin A, Szabo C (2006) Therapeutic effects of xanthine oxidase inhibitors: renaissance half a century after the discovery of allopurinol. Pharmacol Rev 58:87-114

77. Lloyd RV, Shuster L, Mason RP (1993) Reexamination of the microsomal transformation of $\mathrm{N}$-hydroxynorcocaine to norcocaine nitroxide. Mol Pharmacol 43:645-648

78. Shuster L, Casey E, Welankiwar SS (1983) Metabolism of cocaine and norcocaine to $N$-hydroxynorcocaine. Biochem Pharmacol 32:3045-3051

79. Rauckman EJ, Rosen GM, Cavagnaro J (1982) Norcocaine nitroxide. A potential hepatotoxic metabolite of cocaine. Mol Pharmacol 21:458-463

80. Li G, Xiao Y, Zhang L (2005) Cocaine induces apoptosis in fetal rat myocardial cells through the p38 mitogen-activated protein kinase and mitochondrial/cytochrome c pathways. J Pharmacol Exp Ther 312:112-119

81. Xiao Y, He J, Gilbert RD, Zhang L (2000) Cocaine induces apoptosis in fetal myocardial cells through a mitochondriadependent pathway. J Pharmacol Exp Ther 292:8-14

82. He J, Xiao Y, Casiano CA, Zhang L (2000) Role of mitochondrial cytochrome $\mathrm{c}$ in cocaine-induced apoptosis in coronary artery endothelial cells. J Pharmacol Exp Ther 295:896-903

83. Mukhopadhyay P, Horvath B, Zsengeller Z, Batkai S, Cao Z, Kechrid M, Holovac E, Erdelyi K, Tanchian G, Liaudet L, Stillman IE, Joseph J, Kalyanaraman B, Pacher P (2012) Mitochondrial reactive oxygen species generation triggers inflammatory response and tissue injury associated with hepatic ischemiareperfusion: therapeutic potential of mitochondrially targeted antioxidants. Free Radic Biol Med 53:1123-1138 
84. Mukhopadhyay P, Horvath B, Zsengeller Z, Zielonka J, Tanchian G, Holovac E, Kechrid M, Patel V, Stillman IE, Parikh SM, Joseph J, Kalyanaraman B, Pacher P (2012) Mitochondrial-targeted antioxidants represent a promising approach for prevention of cisplatin-induced nephropathy. Free Radic Biol Med 52:497-506

85. Rudis MI, Basha MA, Zarowitz BJ (1996) Is it time to reposition vasopressors and inotropes in sepsis? Crit Care Med 24:525-537
86. Galougahi KK, Liu CC, Bundgaard H, Rasmussen HH (2012) $\beta$ Adrenergic regulation of the cardiac $\mathrm{Na}^{+}-\mathrm{K}^{+}$ATPase mediated by oxidative signaling. Trends Cardiovasc Med 22:83-87

87. Hollenberg SM (2009) Inotrope and vasopressor therapy of septic shock. Crit Care Clin 25:781-802 